\title{
Inverse association between cancer and Alzheimer's disease: results from the Framingham Heart Study
}

\author{
(c) $\underset{1}{(1)(8)}$ OPEN ACCESS
}

\author{
Jane A Driver assistant professor of medicine ${ }^{123}$, Alexa Beiser professor of neurology and \\ biostatistics $^{456}$, Rhoda Au associate professor of neurology ${ }^{4}$, Bernard E Kreger assistant professor \\ of medicine ${ }^{67}$, Greta Lee Splansky director of operations, Framingham Heart Study ${ }^{6}$, Tobias Kurth \\ director of research ${ }^{38}$, Douglas P Kiel professor of medicine ${ }^{9}$, Kun Ping Lu professor of medicine ${ }^{9}$, \\ Sudha Seshadri associate professor of neurology ${ }^{4}$, Phillip A Wolf professor of neurology ${ }^{4}$
}

${ }^{1}$ Geriatric Research Education and Clinical Center and Boston VA Medical Center, Boston, MA 02130, USA; ${ }^{2}$ Division of Aging, Brigham and Women's Hospital, Boston, MA, USA; ${ }^{3}$ Division of Preventive Medicine, Brigham and Women's Hospital, Boston, MA, USA; ${ }^{4}$ Department of Neurology, School of Medicine, Boston University, Boston, MA, USA; ${ }^{5}$ Department of Biostatistics, School of Public Health, Boston University, Boston, MA, USA; ${ }^{6}$ Framingham Heart Study, National Heart, Lung, and Blood Institute, Framingham, MA, USA; ${ }^{7}$ Department of Medicine, Boston University, Boston, MA, USA; ${ }^{8}$ INSERM Unit 708-Neuroepidemiology, Bordeaux, France, and University of Bordeaux, France; ${ }^{9}$ Department of Medicine, Beth Israel Deaconess Medical Center, Harvard Medical School, Boston, MA, USA

\begin{abstract}
Objectives To relate cancer since entry into the Framingham Heart Study with the risk of incident Alzheimer's disease and to estimate the risk of incident cancer among participants with and without Alzheimer's disease.

Design Community based prospective cohort study; nested age and sex matched case-control study.

Setting Framingham Heart Study, USA.

Participants 1278 participants with and without a history of cancer who were aged 65 or more and free of dementia at baseline (1986-90).

Main outcome measures Hazard ratios and 95\% confidence intervals for the risks of Alzheimer's disease and cancer.

Results Over a mean follow-up of 10 years, 221 cases of probable Alzheimer's disease were diagnosed. Cancer survivors had a lower risk of probable Alzheimer's disease (hazard ratio $0.67,95 \%$ confidence interval 0.47 to 0.97 ), adjusted for age, sex, and smoking. The risk was lower among survivors of smoking related cancers $(0.26,0.08$ to 0.82$)$ than among survivors of non-smoking related cancers $(0.82,0.57$ to 1.19). In contrast with their decreased risk of Alzheimer's disease, survivors of smoking related cancer had a substantially increased risk of stroke $(2.18,1.29$ to 3.68$)$. In the nested case-control analysis, participants with probable Alzheimer's disease had a lower risk of subsequent cancer $(0.39,0.26$ to 0.58$)$ than reference participants, as did participants with any Alzheimer's disease (0.38) and any dementia (0.44).
\end{abstract}

Conclusions Cancer survivors had a lower risk of Alzheimer's disease than those without cancer, and patients with Alzheimer's disease had a lower risk of incident cancer. The risk of Alzheimer's disease was lowest in survivors of smoking related cancers, and was not primarily explained by survival bias. This pattern for cancer is similar to that seen in Parkinson's disease and suggests an inverse association between cancer and neurodegeneration.

\section{Introduction}

Limited data suggest that cancer survivors have a decreased risk of Alzheimer's disease and that people with Alzheimer's disease have lower rates of cancer. ${ }^{1-6}$ Evidence of an inverse relation between Parkinson's disease and most cancers is now convincing. ${ }^{7-13}$ A link between cancer and neurodegeneration is plausible as they share several genes and biological pathways, including inappropriate activation and deregulation of the cell cycle. ${ }^{14-22}$ Signaling along these pathways results in opposite end points: in the case of cancer, uncontrolled cell proliferation, and in the case of neurodegeneration, apoptotic cell death. Proteins such as p53, a major regulator of apoptosis, and Pin1, which has a dual role in cell cycle control and protein folding, play a key part in the pathophysiology of both Alzheimer's disease and cancer. ${ }^{15} \mathrm{~A}$ better understanding of the biological links between these two families of diseases is already opening new therapeutic horizons.

In one population based cohort study, people with prevalent cancer had a $43 \%$ lower risk of ever developing Alzheimer's disease, and those with prevalent Alzheimer's disease had a $69 \%$ lower risk of being admitted to hospital for cancer. ${ }^{4}$ Although these results are intriguing, establishing a relation 
between age related diseases is complex, and several issues must be dealt with before concluding that this represents a true association..$^{23}$ Because severe cognitive impairment leads to decreased screening and reporting of cancer symptoms, ${ }^{24}{ }^{25}$ it is difficult to know to what extent lower cancer rates in people with Alzheimer's disease are caused by decreased incidence or under-diagnosis. For this reason, assessing the incidence of Alzheimer's disease among cancer survivors who are cognitively intact at baseline is the preferable analysis. Here the major challenge is the problem of selective mortality, since cancer survivors may have a lower risk of Alzheimer's disease simply because they are more likely to die before they can develop it. Available studies have not sufficiently tackled the problems of selective mortality. Additional limitations of previous analyses are the exclusion from analysis of incident cancers that develop after baseline but before Alzheimer's disease and reliance on self report or medical record systems to identify cancer. We investigated the relation between cancer and Alzheimer's disease using data from the Framingham Heart Study, a prospective cohort with frequent examinations of participants, prospective validation of both Alzheimer's disease and cancer, and over 50 years of follow-up.

\section{Methods}

The Framingham Heart Study is a longitudinal community based cohort study of cardiovascular risk factors that started in 1948 in Framingham, Massachusetts, United States. The original cohort comprised 5209 participants (2336 men and 2873 women) aged 28-62 at the first examination. In 1971, children of the original cohort and their spouses were recruited to form the offspring cohort (5214 participants). Participants have undergone direct evaluations, including a medical history, physical examination, and laboratory testing every two years in the original cohort and about every four years in the offspring cohort. The study design and entry criteria for both cohorts have been described in detail elsewhere. ${ }^{26}$ Participants of the original cohort aged 65 and older who were free of dementia and attended examination cycle 20 (1986-90) comprise the sample for our primary investigation $(\mathrm{n}=1278)$. We followed these participants for incident dementia for a mean of 10 years. The nested case-control study comprised participants from both the original and the offspring cohorts $(n=1485)$. All participants gave written informed consent.

\section{Ascertainment of cancer cases}

We identified possible cancer cases in the Framingham study at routine examinations or, if participants did not attend an examination, by postal surveys or telephone interviews for updates on health history. Cases were also identified through surveillance of admissions to the local Framingham hospital and from death records. Once a case was identified, we confirmed the diagnosis from the patient's medical records, including pathology reports. Two independent people reviewed the medical records. Most cancers were confirmed by pathology reports, and fewer than $3.4 \%$ of diagnoses were based solely on death certificates or clinical diagnoses. ${ }^{27} \mathrm{We}$ coded primary cancers using the World Health Organization ICD-O (international classification of diseases) classification. For this analysis we did not include non-malignant neoplasms and non-melanoma skin cancers in the definition of cancer.

\section{Ascertainment of dementia cases}

Since examination cycle 14 in the original cohort and examination 2 in the offspring cohort, a dementia-free cohort of 7809 participants has been under continuous surveillance for the development of dementia and Alzheimer's disease. The Folstein mini-mental state examination ${ }^{28}$ was administered at regular cycle examinations, and participants who scored below an education based cut-off point or had a 3 point decrement in their score from a preceding examination (or 5 point decrement overall) were referred for more indepth testing. Participants also underwent an indepth evaluation if they or someone in their family reported symptoms of memory loss or were referred by a Framingham study physician or staff member for evaluation of neurological symptoms. A panel of at least one neurologist and one neuropsychologist determined cases of dementia, dates of diagnosis, and subtypes using data, where available, from the neurologist's examination, neuropsychological test performance, Framingham study records, hospital records, information from primary care physicians, interviews with the families, computed tomography and magnetic resonance imaging records, and confirmation of autopsy findings. Dementia was required to be present for at least six months of follow-up before the diagnosis was confirmed. All participants identified as having dementia had at least mild severity by the clinical dementia rating score of 1 or more. Cases of Alzheimer's disease met the National Institute of Neurological and Communicative Disorders and Stroke and the Alzheimer's Disease and Related Disorders Association criteria for possible and probable Alzheimer's disease. ${ }^{29}$ We classified dementia as any dementia (met the criteria for any dementia, including Alzheimer's disease), possible Alzheimer's disease (met the clinical criteria for Alzheimer's disease but with an atypical course or evidence of a second process contributing to the dementia), and probable Alzheimer's disease (met the criteria for Alzheimer's disease without evidence of another process contributing to the dementia).

\section{Assessment of covariates}

From the baseline visit (examination 20) we obtained data on personal characteristics (age, sex, and education) and laboratory test results (homocysteine levels and apolipoprotein E genotype). We collected information on cancer risk factors (tobacco use and body mass index) at baseline and updated this periodically throughout the study. For the case-control study, we used the covariates closest to the matching date.

\section{Statistical analyses Prospective cohort study}

Participants contributed up to 22 years of follow-up from the baseline examination to the development of dementia, death, or the last evaluation. We used Cox proportional hazard models to determine the hazard ratio and $95 \%$ confidence intervals for the risk of any dementia, any Alzheimer's disease (possible or probable), and probable Alzheimer's disease in those with and without a history of verified cancer. The cancer history variable was updated to include cases of incident cancer that occurred during follow-up after baseline. We carried out separate analyses for participants with any cancer (excluding non-melanoma skin cancer), smoking related cancers (oral, pharynx, larynx, oesophagus, stomach, pancreas, lung, cervix, bladder, and kidney $)^{30}$, and non-smoking related cancers. The primary models were adjusted for age, sex, and smoking. We then repeated the analysis in a smaller subset of patients with data on other risk factors for Alzheimer's disease: apolipoprotein E4 status, educational level, and plasma homocysteine level..$^{30-32}$

To explore whether the relation between cancer and Alzheimer's disease might be mainly due to selective mortality, we first 
restricted the analysis to participants who survived at least to age 80 . If the association was predominantly due to the death of cancer survivors, then it should be diminished when these patients were excluded. We then investigated the relation between history of cancer at examination 20 (baseline) and a different neurological outcome-namely, the subsequent risk of incident stroke. If a decreased risk of cancer in patients with Alzheimer's disease was primarily due to their increased mortality rate, then they would be expected to have a lower rate of stroke as well.

\section{Nested case-control study}

To evaluate the relation between dementia and subsequent cancer, we matched each dementia case with up to three controls of the same age and sex who were free of dementia at the time of dementia diagnosis of the case (index date). Both cases and reference participants were free of cancer as of the index date. Participants who eventually developed dementia were considered potential controls up to five years before their data of dementia diagnosis (to avoid subclinical dementia in controls). We used Cox models to determine the hazard of incident cancer in dementia cases compared with the reference participants. Models were adjusted for tobacco use and body mass index. Data on covariates was taken from the examination closest to the index date. We calculated the cumulative incidence of cancer in those with and without Alzheimer's disease adjusted for age, sex, body mass index, and smoking.

\section{Results}

At examination 20 (baseline), 1278 participants (38.8\% men) aged 65 or older had normal cognitive status. The mean age among cancer survivors $(n=176)$ was 77 years and among those with no history of cancer $(n=1102)$ was 76 years (table $1 \Downarrow)$. Educational level, positivity for apolipoprotein E4, and homocysteine level did not differ substantially between those with and without cancer. Overall, 323 cases of dementia were diagnosed over a mean of 10 years of follow-up. Of these, 221 $(86 \%)$ met the criteria for probable Alzheimer's disease and 36 for possible Alzheimer's disease (18 had Alzheimer's disease with stroke and 18 had both Alzheimer's disease and vascular dementia). Of the 66 patients with non-Alzheimer's disease, 24 had Lewy body dementia, 15 had vascular dementia, two had frontotemporal dementia, and 25 were classified as having "other" dementia.

\section{Cancer history and risk of Alzheimer's disease}

At baseline 176 participants had a history of cancer, and during follow-up an additional 247 people were diagnosed as having incident cancer but before the diagnosis of Alzheimer's disease. Cancers at baseline were more likely to be screening related and non-smoking related than incident cancers (table $2 \Downarrow$ ). Cancers with high lethality such as those of the lung, pancreas, and brain were much more common among incident cancers. Cancer survivors had a substantially lower risk of probable Alzheimer's disease (hazard ratio $0.67,95 \%$ confidence interval 0.47 to 0.97 ), adjusted for age, sex, and smoking (table $3 \Downarrow$ ), but the lower risks of any Alzheimer's disease (0.81) and any dementia (0.83) did not reach statistical significance. The risk of probable Alzheimer's disease was lower among survivors of smoking related cancers $(0.26,0.08$ to 0.82$)$ than among those with non-smoking related cancers $(0.82,0.57$ to 1.19$)$. Further adjustment for education, apolipoprotein E4 genotype, and homocysteine level gave slightly higher risk estimates, but the loss of statistical significance was possibly due to limited power in this smaller subset (table 3). Limiting the analysis to participants who survived at least to age 80 did not change the inverse association between cancer history and probable Alzheimer's disease $(0.68,0.47$ to 0.99 , table $4 \Downarrow)$. In contrast with their substantially lower risk of Alzheimer's disease, survivors of smoking related cancer had an increased risk of incident stroke $(2.18,1.29$ to 3.68$)$, which was also seen among those who survived to age $80(2.25,1.29$ to 3.95$)$.

\section{Incident Alzheimer's disease and risk of cancer}

Overall, 495 cases of any dementia, 49 of possible Alzheimer's disease, and 327 of probable Alzheimer's disease were prospectively identified. Up to three dementia-free controls were matched to each case. Overall, 41 cases (8\%) and 211 controls $(14 \%)$ developed incident cancer. Table $5 \Downarrow$ shows the frequency of individual cancer types by case-control status. In total, $6.9 \%(\mathrm{n}=102)$ of controls were diagnosed as having screening related cancer compared with $3.4 \%(n=17)$ of cases. In the age matched group, the risk of subsequent cancer was substantially decreased for those with any dementia $(0.44,0.32$ to 0.61 ), any Alzheimer's disease $(0.45,0.24$ to 0.84$)$, and probable Alzheimer's disease $(0.39,0.26$ to 0.58 , table $6 \Downarrow)$. When adjusted for smoking and body mass index, the decreased risk of cancer remained statistically significant and became even lower. Over the follow-up period, 57 controls (17\%) developed probable Alzheimer's disease.

\section{Discussion}

In this prospective cohort study, cancer survivors had a $33 \%$ decreased risk of developing probable Alzheimer's disease compared with people without cancer. The "protective effect" of previous cancer was greater for smoking related cancers than for non-smoking related cancers. The inverse association did not change when participants who died were excluded, and was not seen when stroke was used as an alternative outcome, suggesting it was not simply an artefact of decreased survival in patients with cancer. In the case-control analysis, patients with probable Alzheimer's disease had a $61 \%$ decreased risk of incident cancer. When all dementias were included, the risk became slightly higher. Patients with dementia were less likely to develop screening related cancers than those without dementia, suggesting that at least some of the decreased risk is because of under-diagnosis.

\section{Strengths and limitations of the study}

Our analysis has several important strengths. We prospectively defined cancer and Alzheimer's disease in the Framingham Heart Study over its more than 50 years of follow-up, so that our cases represent incident disease. Nearly all malignancies in the population were captured. We updated our cancer variable to include the many incident cases that occurred after baseline, during follow-up. This strengthened the negative association between cancer and Alzheimer's disease (data not shown), and suggests that analyses that do not include incident cancer may underestimate the association. Finally, we carried out two specific analyses to tackle the critical problem of survival bias. Several limitations should also be considered. Firstly, our cohort, by definition, did not include people who died of cancer before study baseline. It is unknown whether people who died of cancer before the age of 65 would have had the same risk as those of survivors. As in any longitudinal study, participants with long follow-up represent a select population, and this should be kept 
in mind when interpreting our results. Even complex techniques used for missing data are not able to fully correct for this selection bias. ${ }^{33}$ However, the inverse association observed in this study was not primarily due to survival bias, at least during follow-up. We did not have the power to look at the relation between Alzheimer's disease and individual cancer types, or to compare the relation between cancer and other types of dementia. Cohorts in which both Alzheimer's disease and cancer are carefully defined are by definition not of the size required for such analyses. We were unable to stratify our results by race, as the participants in our study were mainly white. Some cases of vascular dementia were present in those who met the criteria for possible Alzheimer's disease, but, if anything, this would have biased our results towards the null. Finally, owing to the relatively small numbers of patients with cancer in our analysis, we were not able to stratify analyses by whether patients had or had not received treatment for cancer.

\section{Comparison with previous studies}

Our findings are similar to those of the only two available prospective studies. In a longitudinal memory cohort of 594 patients, those with prevalent cancer at baseline seemed to develop Alzheimer's disease at a lower rate (hazard ratio 0.40, $95 \%$ confidence interval 0.12 to 1.13 ) than those with no history of cancer. ${ }^{3}$ In an analysis of the cognition cohort of the Cardiovascular Health Study $(\mathrm{n}=3020)$, a history of cancer at baseline conferred a lower risk of probable Alzheimer's disease (hazard ratio $0.57,95 \%$ confidence interval 0.36 to 0.90$){ }^{4}$ Similar to their results, we found that the inverse relation became stronger as we excluded non-Alzheimer's and mixed dementias. Our risk estimates for incidence of cancer among those with and without Alzheimer's disease were essentially the same as that of Roe and colleague's study $(0.39,0.21$ to 0.74$){ }^{3}$ The inverse relation decreased only slightly when we included all other dementias, and it was clear in our cohort that patients with dementia had fewer screening related cancers. This suggests that under-diagnosis in people with cognitive impairment explains at least part of the decreased incidence of cancer in patients with Alzheimer's disease. However, it is unlikely to explain all of it. Two studies found a substantially decreased prevalence of cancer on autopsy among patients with Alzheimer's disease compared with age matched controls without dementia. ${ }^{15}$ In their second study, Roe and colleagues found that admission to hospital for cancer was low among patients with Alzheimer's disease (hazard ratio 0.31, 0.12 to 0.86 ) but not in those with vascular dementia. Finally, in a unique study of 2222 Japanese survivors of the atomic bomb, people with clinically diagnosed Alzheimer's disease had a 70\% decreased risk of previous cancer compared with age matched participants without dementia, whereas those with vascular dementia had a fourfold increased risk of cancer. Clearly it will never be possible to completely adjust for reporting and diagnostic bias in elderly patients with dementia, but together these findings suggest a specific inverse relation between cancer and Alzheimer's disease.

We found that survivors of smoking related cancer had a substantially lower risk of Alzheimer's disease than survivors of non-smoking related cancer-a pattern similar to that seen in Parkinson's disease. In a recent meta-analysis of 107598 patients with Parkinson's disease, the aggregate relative risk was 0.73 (95\% confidence interval 0.63 to 0.83 ) for any cancer, 0.61 ( 0.58 to 0.65$)$ for smoking related cancers, and $0.80(0.77$ to 0.84 ) for non-smoking related cancers. ${ }^{7}$ A lower rate of smoking related cancers might be expected in patients with Parkinson's disease owing to its well established negative association with smoking, ${ }^{34}$ but, in the case of Alzheimer's disease, the association with smoking was strongly positive. ${ }^{35}$ In our analysis, higher mortality among those with smoking related cancer did not explain the lower risk of Alzheimer's disease. Perhaps characteristics that allow someone to survive a smoking related cancer are particularly protective against neurodegeneration. That Alzheimer's disease and Parkinson's disease are associated with the same unusual pattern for cancer suggests the presence of as yet uncovered biological connections between neurodegeneration and carcinogenesis.

\section{Biological plausibility}

Although cancer survivors may have some protection from neurodegenerative diseases, the more hopeful significance of these findings will come from the underlying biology that explains this relation. ${ }^{14}{ }^{16} \mathrm{~A}$ genetic propensity against apoptosis might protect people from cancer while increasing their risk of neurodegeneration, as seen in some polymorphisms of the tumour suppressor gene p53. ${ }^{36} \mathrm{~A}$ specific link between Alzheimer's disease and cancer is the protein Pin1, a unique enzyme that plays a part in protein folding as well as cell cycle control. ${ }^{15} 173738$ Many tumours in humans over-express Pin $1,{ }^{39}$ whereas its function is low in the brain tissue of people with Alzheimer's disease. ${ }^{39-42}$ As Pin1 is necessary for cell division, its inhibition causes regression of tumours, ${ }^{43}$ whereas in mouse models of Alzheimer's disease its upregulation in postnatal neurons reverses neurodegeneration. ${ }^{44}$ Moreover, Pin1 promoter single nucleotide polymorphisms that inhibit Pin1 expression are associated with an increased risk of Alzheimer's disease ${ }^{45}$ but a decreased risk of cancer. ${ }^{46}$ Drugs that can modulate Pin1 are being sought as novel therapeutic agents.

An interesting unanswered question is whether treatment for cancer modulates the risk of Alzheimer's disease. In theory, chemotherapy might protect neurons susceptible to Alzheimer's disease by suppressing inflammation ${ }^{47}$ or blocking entry into the cell cycle ${ }^{48}$ both key steps in the pathway of neurodegeneration. However, to our knowledge there is no epidemiological evidence linking chemotherapy to a decreased risk of Alzheimer's disease. On the other hand, cognitive impairment is a well described complication of chemotherapy and has been associated with long term changes in brain structure and function in animal models. ${ }^{49}$ Survivors of breast cancer who received adjuvant chemotherapy were more likely to develop dementia in one study ${ }^{50}$ but not in another. ${ }^{51}$ Cranial irradiation is clearly associated with neuronal damage and loss, not neuroprotection. ${ }^{52}$ Thus, although we did not account for cancer therapy in our analysis, available evidence suggests that, if anything, it would have biased our results towards the null.

\section{Conclusions and future work}

The results of our analysis support the possibility of a true inverse relation between cancer and Alzheimer's disease. This study is, however, only exploratory and further work is needed to establish better the link between these two groups of diseases. Further insights will possibly be gained from analyses in large clinical and administrative databases with the power to look at the relation between Alzheimer's disease and individual types of cancer. The potential impact of cancer treatment on risk of Alzheimer's disease is another interesting area for future work. Presently there are few curative treatments for cancer and not even one disease modifying drug for Alzheimer's disease. Our data suggest that vulnerability to cancer may actually protect against neurodegeneration, and vice versa. A further understanding of the basis for this inverse relation may lead to 
novel therapies and should remain a focus of intense basic and translational research.

Contributors: JAD, AB, KPL, and DPK conceived and designed the study. BEK, GLS, and PAW acquired the data. JAD, AB, RA, and SS analysed and interpreted the data. JAD drafted the manuscript. $A B, R A$, $B E K, G L S, T K, D P K, K P L, S S$, and PAW critically revised the manuscript. $A B$ carried out the statistical analysis. JAD and PAW obtained the funding. RA, BEK, GLS, TK, DPK, KPL, SS, and PAW supervised the study. JAD and $A B$ had full access to all the data in the study. JAD takes responsibility for the integrity of the data and the accuracy of the data analysis and is guarantor.

Funding: JAD was funded by a Veterans' Administration career development award. The Framingham Heart Study is supported by an National Heart, Lung, and Blood Institute contract (N01-HC-25195) and by grants from the National Institutes of Aging (AG16495 and AG08122) and National Institute of Neurological Disorders and Stroke (NS17950). The authors' work was independent of the funders. The funders had no role in the design and conduct of the study; collection, management, analysis, and interpretation of the data; and preparation, review, or approval of the manuscript.

Competing interests: All authors have completed the ICMJE uniform disclosure form at www.icmje.org/coi_disclosure.pdf (available on request from the corresponding author) and declare: no support from any organisation for the submitted work; no financial relationships with any organisations that might have an interest in the submitted work in the previous three years; and no other relationships or activities that could appear to have influenced the submitted work.

Ethical approval: The Framingham study protocols and participant consent forms were approved by the institutional review board of Boston University School of Medicine.

Data sharing: No additional data available.

Corsellis J. Mental illness and the ageing brain. Oxford University Press, 1962.

2 DeSouky AL. The relationship between cancer and Alzheimer's disease. J Am Geriatr Soc 1992;40:1075.

3 Roe CM, Behrens MI, Xiong C, Miller JP, Morris JC. Alzheimer disease and cancer. Neurology 2005;64:895-8.

4 Roe CM, Fitzpatrick AL, Xiong C, Sieh W, Kuller L, Miller JP, et al. Cancer linked to Alzheimer disease but not vascular dementia. Neurology 2010;74:106-12.

5 Tirumalasetti F, Han L, Birkett DP. The relationship between cancer and Alzheimer's disease. J Am Geriatr Soc 1991;39:840.

6 Yamada M, Sasaki H, Mimori Y, Kasagi F, Sudoh S, Ikeda J, et al. Prevalence and risks of dementia in the Japanese population: RERF's adult health study of Hiroshima subjects. Radiation Effects Research Foundation. J Am Geriatr Soc 1999;47:189-95.

7 Bajaj A, Driver JA, Schernhammer ES. Parkinson's disease and cancer risk: a systematic review and meta-analysis. Cancer Causes Control 2010;21:697-707.

8 Driver JA, Kurth T, Buring JE, Gaziano JM, Logroscino G. Prospective case-control stud of nonfatal cancer preceding the diagnosis of Parkinson's disease. Cancer Causes Control 2007:18:705-11.

9 Driver JA, Logroscino G, Buring JE, Gaziano JM, Kurth T. A prospective cohort study of cancer incidence following the diagnosis of Parkinson's disease. Cancer Epidemiol Biomarkers Prev 2007;16:1260-5.

10 Elbaz A, Peterson BJ, Bower JH, Yang P, Maraganore DM, McDonnell SK, et al. Risk of cancer after the diagnosis of Parkinson's disease: a historical cohort study. Mov Disord 2005:20:719-25.

11 Elbaz A, Peterson BJ, Yang P, Van Gerpen JA, Bower JH, Maraganore DM, et al. Nonfatal cancer preceding Parkinson's disease: a case-control study. Epidemiology 2002;13:157-64

12 Olsen JH, Friis S, Frederiksen K, McLaughlin JK, Mellemkjaer L, Moller H. Atypical cance pattern in patients with Parkinson's disease. Br J Cancer 2005;92:201-5.

13 Olsen $\mathrm{JH}$, Tangerud K, Wermuth L, Frederiksen K, Friis S. Treatment with levodopa and risk for malignant melanoma. Mov Disord 2007;22:1252-7.

14 Behrens MI, Lendon C, Roe CM. A common biological mechanism in cancer and Alzheimer's disease? Curr Alzheimer Res 2009;6:196-204

15 Driver JA, Lu KP. Pin1: a new genetic link between Alzheimer's disease, cancer and aging. Curr Aging Sci 2010;3:158-65.

16 Husseman JW, Nochlin D, Vincent I. Mitotic activation: a convergent mechanism for a cohort of neurodegenerative diseases. Neurobiol Aging 2000;21:815-28.

17 Lu KP. Pinning down cell signaling, cancer and Alzheimer's disease. Trends Biochem Sci 2004;29:200-9.

18 Lu KP, Liou YC, Vincent I. Proline-directed phosphorylation and isomerization in mitotic regulation and in Alzheimer's disease. Bioessays 2003:25:174-81.

19 Raina AK, Zhu X, Rottkamp CA, Monteiro M, Takeda A, Smith MA. Cyclin' toward dementia: cell cycle abnormalities and abortive oncogenesis in Alzheimer disease. $J$ Neurosci Res 2000;61:128-33.

20 Staropoli JF. Tumorigenesis and neurodegeneration: two sides of the same coin? Bioessays 2008;30:719-27.
21 Wang W, Bu B, Xie M, Zhang M, Yu Z, Tao D. Neural cell cycle dysregulation and central nervous system diseases. Prog Neurobiol 2009:89:1-17.

22 West AB, Dawson VL, Dawson TM. To die or grow: Parkinson's disease and cancer. Trends Neurosci 2005;28:348-52.

23 Bennett DA. Is there a link between cancer and Alzheimer disease? Neurology 2010;75:1216-7.

24 Marwill SL, Freund KM, Barry PP. Patient factors associated with breast cancer screening among older women. J Am Geriatr Soc 1996;44:1210-4.

25 Scherder E, Bouma A, Borkent M, Rahman O. Alzheimer patients report less pain intensity and pain affect than non-demented elderly. Psychiatry 1999;62:265-72.

26 Dawber TR, Meadors GF, Moore FE Jr. Epidemiological approaches to heart disease: the Framingham Study. Am J Public Health Nations Health 1951;41:279-81.

27 Kreger BE, Splansky GL, Schatzkin A. The cancer experience in the Framingham Heart Study cohort. Cancer 1991;67:1-6.

28 Folstein MF, Folstein SE, McHugh PR. "Mini-mental state." A practical method for grading the cognitive state of patients for the clinician. J Psychiatr Res 1975;12:189-98.

29 McKhann G, Drachman D, Folstein M, Katzman R, Price D, Stadlan EM. Clinical diagnosis of Alzheimer's disease: report of the NINCDS-ADRDA Work Group under the auspices of Department of Health and Human Services Task Force on Alzheimer's Disease. Neurology 1984;34:939-44.

30 Centers for Disease Control and Prevention, Office on Smoking and Health. The health consequences of smoking: a report of the surgeon general. Centers for Disease Control and Prevention, 2004.

31 Seshadri S, Beiser A, Selhub J, Jacques PF, Rosenberg IH, D'Agostino RB, et al. Plasma homocysteine as a risk factor for dementia and Alzheimer's disease. N Engl J Med 2002;346:476-83.

32 Seshadri S, Drachman DA, Lippa CF. Apolipoprotein E epsilon 4 allele and the lifetime risk of Alzheimer's disease. What physicians know, and what they should know. Arch Neurol 1995;52:1074-9.

33 Euser SM, Schram MT, Hofman A, Westendorp RG, Breteler MM. Measuring cognitive function with age: the influence of selection by health and survival. Epidemiology 2008;19:440-7.

34 Hernan MA, Takkouche B, Caamano-Isorna F, Gestal-Otero JJ. A meta-analysis of coffee drinking, cigarette smoking, and the risk of Parkinson's disease. Ann Neurol 2002;52:276-84

35 Rusanen M, Kivipelto M, Quesenberry CP Jr, Zhou J, Whitmer RA. Heavy smoking in midlife and long-term risk of Alzheimer disease and vascular dementia. Arch Intern Med 2011;171:333-9.

36 Van Heemst D, Mooijaart SP, Beekman M, Schreuder J, de Craen AJ, Brandt BW, et al. Variation in the human TP53 gene affects old age survival and cancer mortality. Exp Gerontol 2005;40:11-5.

37 Lu KP, Hanes SD, Hunter T. A human peptidyl-prolyl isomerase essential for regulation of mitosis. Nature 1996;380:544-7.

38 Lu KP, Zhou XZ. The prolyl isomerase PIN1: a pivotal new twist in phosphorylation signalling and disease. Nat Rev Mol Cell Biol 2007:8:904-16.

39 Bao L, Sauter G, Sowadski J, Lu KP, Wang D. Prevalent overexpression of prolyl isomerase Pin1 in human cancers. Am J Pathol 2004;164:1727-37.

40 Liou Y-C, Sun A, Ryo A, Zhou XZ, Yu Z-X, Huang H-K, et al. Role of the prolyl isomerase Pin1 in protecting against age-dependent neurodegeneration. Nature 2003;424:556-61.

41 Lu PJ, Wulf G, Zhou XZ, Davies P, Lu KP. The prolyl isomerase Pin1 restores the function of Alzheimer-associated phosphorylated tau protein. Nature 1999;399:784-8.

42 Sultana R, Boyd-Kimball D, Poon HF, Cai J, Pierce WM, Klein JB, et al. Oxidative modification and down-regulation of Pin1 in Alzheimer's disease hippocampus: a redox proteomics analysis. Neurobiol Aging 2006;27:918-25.

43 Wulf G, Garg P, Liou YC, Iglehart D, Lu KP. Modeling breast cancer in vivo and ex vivo reveals an essential role of Pin1 in tumorigenesis. EMBO J 2004;23:3397-407.

44 Lim J, Balastik M, Lee TH, Nakamura K, Liou YC, Sun A, et al. Pin1 has opposite effects on wild-type and P301L tau stability and tauopathy. J Clin Invest 2008;118:1877-89.

45 Segat L, Pontillo A, Annoni G, Trabattoni D, Vergani C, Clerici M, et al. PIN1 promoter polymorphisms are associated with Alzheimer's disease. Neurobiol Aging 2007;28:69-74.

46 Lu J, Hu Z, Wei S, Wang LE, Liu Z, El-Naggar AK, et al. A novel functional variant $(-842 G>C)$ in the PIN1 promoter contributes to decreased risk of squamous cell carcinoma of the head and neck by diminishing the promoter activity. Carcinogenesis 2009;30:1717-21.

47 Zotova E, Nicoll JA, Kalaria R, Holmes C, Boche D. Inflammation in Alzheimer's disease: relevance to pathogenesis and therapy. Alzheimers Res Ther 2010;2:1.

48 Webber KM, Raina AK, Marlatt MW, Zhu X, Prat MI, Morelli L, et al. The cell cycle in Alzheimer disease: a unique target for neuropharmacology. Mech Ageing Dev 2005;126:1019-25.

49 Seigers R, Fardell JE. Neurobiological basis of chemotherapy-induced cognitive impairment: a review of rodent research. Neurosci Biobehav Rev 2011;35:729-41.

50 Heck JE, Albert SM, Franco R, Gorin SS. Patterns of dementia diagnosis in surveillance, epidemiology, and end results breast cancer survivors who use chemotherapy. J Am Geriatr Soc 2008;56:1687-92.

51 Baxter NN, Durham SB, Phillips KA, Habermann EB, Virning BA. Risk of dementia in older breast cancer survivors: a population-based cohort study of the association with adjuvant chemotherapy. J Am Geriatr Soc 2009;57:403-11.

52 Surma-aho O, Niemela M, Vilkki J, Kouri M, Brander A, Salonen O, et al. Adverse long-term effects of brain radiotherapy in adult low-grade glioma patients. Neurology 2001;56:1285-90.

Accepted: 29 December 2011

\section{Cite this as: BMJ 2012;344:e1442}

This is an open-access article distributed under the terms of the Creative Commons Attribution Non-commercial License, which permits use, distribution, and reproduction in any medium, provided the original work is properly cited, the use is non commercial and is otherwise in compliance with the license. See: http://creativecommons.org/licenses/by$\mathrm{nc} / 2.0 /$ and http://creativecommons.org/licenses/by-nc/2.0/legalcode. 


\section{What is already known on this topic}

Parkinson's disease is associated with a decreased risk of most cancers, and growing evidence suggests that cancer and neurodegenerative diseases share genes and biological pathways

Limited data suggest an inverse relation between cancer and Alzheimer's disease

It is, however, unclear if the association might be result from selective mortality in cancer survivors or under-diagnosis in patients with Alzheimer's disease

\section{What this study adds}

Survivors of any cancer had a $33 \%$ lower risk of incident Alzheimer's disease and survivors of smoking related cancer had a $74 \%$ decreased risk, neither explained by survival bias

Participants with incident Alzheimer's disease had a $61 \%$ decreased risk of developing incident cancer, which may in part be due to under-diagnosis

This unusual pattern for cancer is similar to that seen in Parkinson's disease and suggests an inverse relation between cancer and neurodegeneration

\section{Tables}

\section{Table 1| Characteristics of Framingham Heart Study participants who were free of dementia at examination 20 (baseline), by history of} cancer. Values are numbers (percentages) unless stated otherwise

\begin{tabular}{lcc} 
Characteristics & History of cancer $(\mathbf{n = 1 7 6})$ & No history of cancer $(\mathbf{n}=\mathbf{1 1 0 2})$ \\
Mean (range) age (years) & $77(68-96)$ & $76(68-96)$ \\
\hline Men & $72(41)$ & $424(38)$ \\
\hline Women & $104(59)$ & $678(62)$ \\
\hline Completion of secondary school & $166(72)$ & $679(67)$ \\
\hline Apolipoprotein E4 & $38(25)$ & $200(20)$ \\
\hline Mean (range) homocysteine level $(\mu \mathrm{mol} / \mathrm{L})$ & $12.9(4.1-66.7)$ & $12.8(3.5-61.6)$
\end{tabular}




\begin{tabular}{|c|c|c|c|}
\hline \multirow[b]{2}{*}{ Cancer types } & \multirow[b]{2}{*}{ Total No $(n=423)$} & \multicolumn{2}{|c|}{ No $(\%)$ of cancers } \\
\hline & & Prevalent $(n=176)$ & Incident $(\mathrm{n}=247)$ \\
\hline Smoking related ${ }^{\star}$ & 150 & $54(31)$ & $96(39)$ \\
\hline Non-smoking related & 304 & $127(72)$ & $177(72)$ \\
\hline Cancers on routine screening & 229 & $105(60)$ & $124(50)$ \\
\hline Head and neck & 11 & $8(5)$ & $3(1)$ \\
\hline Oesophagus or stomach & 23 & $9(5)$ & $14(6)$ \\
\hline Colon & 49 & $21(12)$ & $28(11)$ \\
\hline Rectum & 20 & $6(3)$ & $14(6)$ \\
\hline Pancreas & 9 & $0(0)$ & $9(4)$ \\
\hline Lung & 46 & $9(5)$ & $37(15)$ \\
\hline Haematological & 15 & $2(1)$ & $13(5)$ \\
\hline Connective tissue & 6 & $2(1)$ & $4(2)$ \\
\hline Melanoma & 12 & $8(5)$ & $4(2)$ \\
\hline Breast & 83 & $44(25)$ & $39(16)$ \\
\hline Uterus and endometrium & 17 & $13(7)$ & $4(2)$ \\
\hline Cervix & 6 & $5(3)$ & $1(0)$ \\
\hline Ovary & 7 & $3(2)$ & $4(2)$ \\
\hline Prostate & 59 & $21(12)$ & $38(15)$ \\
\hline Bladder & 27 & $17(10)$ & $10(4)$ \\
\hline Kidney & 10 & $4(2)$ & $6(2)$ \\
\hline Brain & 5 & $0(0)$ & $5(2)$ \\
\hline Lymph nodes & 7 & $3(2)$ & $4(2)$ \\
\hline Unknown primary & 5 & $0(0)$ & $5(2)$ \\
\hline Other & 6 & $1 \dagger(17)$ & $5 \ddagger(83)$ \\
\hline
\end{tabular}


Table 3| Association between history of cancer at examination 20 (baseline) and incident dementia in Framingham Heart Study, after adjustment

\begin{tabular}{|c|c|c|c|c|c|}
\hline \multirow[b]{3}{*}{ Model and cancer types } & \multicolumn{2}{|c|}{ No of cancers } & \multicolumn{3}{|c|}{ Hazard ratio $(95 \% \mathrm{Cl})^{*}$} \\
\hline & \multirow[b]{2}{*}{ At baseline } & \multirow[b]{2}{*}{ Incident cases } & \multirow[b]{2}{*}{ Any dementia } & \multicolumn{2}{|c|}{ Alzheimer's disease } \\
\hline & & & & Possible & Probable \\
\hline Model $1(n=1274) \dagger:$ & & & $n=322$ & $\mathrm{n}=256$ & $n=220$ \\
\hline All & 175 & 247 & $0.83(0.63$ to 1.10$)$ & $0.81(0.59$ to 1.11$)$ & $0.67(0.47$ to 0.97$)$ \\
\hline Smoking related§ & 54 & 96 & $0.79(0.45$ to 1.39$)$ & $0.62(0.31$ to 1.26$)$ & 0.26 (0.08 to 0.82$)$ \\
\hline Non-smoking related & 127 & 177 & $0.84(0.62$ to 1.13$)$ & $0.87(0.62$ to 1.21$)$ & $0.82(0.57$ to 1.19$)$ \\
\hline Model $2(n=1037) \uparrow:$ & & & $n=263$ & $n=212$ & $n=185$ \\
\hline All & 133 & 210 & $0.92(0.68$ to 1.26$)$ & $0.90(0.64$ to 1.28$)$ & $0.76(0.52$ to 1.12$)$ \\
\hline Smoking related§ & 40 & 77 & $0.66(0.32$ to 1.33$)$ & $0.62(0.28$ to 1.41$)$ & $0.34(0.11$ to 1.08$)$ \\
\hline Non-smoking related & 97 & 157 & 0.99 (0.72 to 1.38$)$ & 0.99 (0.68 to 1.42$)$ & $0.91(0.61$ to 1.35$)$ \\
\hline
\end{tabular}

${ }^{*}$ Calculated using Cox proportional hazards modelling. †Adjusted for age, sex, smoking, and incident cancer. $\ddagger$ Does not include non-melanoma skin cancers.

$\S$ Defined as cancer of the oral cavity, pharynx, larynx, oesophagus, stomach, pancreas, lung, cervix, bladder, and kidney.

IAdditionally adjusted for apolipoprotein E4 status, education, and homocysteine level. 
Table 4| Association between history of cancer at examination 20 (baseline) and incident dementia in Framingham Heart Study among 995 participants who survived to at least age 80

\begin{tabular}{|c|c|c|c|c|c|}
\hline \multirow[b]{3}{*}{ Cancer types } & \multicolumn{2}{|c|}{ No of cancers } & \multicolumn{3}{|c|}{ Hazard ratio $(95 \% \mathrm{Cl})^{*}$} \\
\hline & \multirow[b]{2}{*}{ At baseline } & \multirow[b]{2}{*}{ Incident cases } & \multirow[t]{2}{*}{ Any dementia $(n=302)$} & \multicolumn{2}{|c|}{ Alzheimer's disease } \\
\hline & & & & Possible $(n=244)$ & Probable $(n=209)$ \\
\hline All & 127 & 183 & $0.87(0.65$ to 1.16$)$ & $0.81(0.46$ to 1.46$)$ & $0.88(0.64$ to 1.20$)$ \\
\hline Smoking related & 37 & 69 & $0.83(0.60$ to 1.15$)$ & $0.68(0.34$ to 1.38$)$ & $0.88(0.62$ to 1.25$)$ \\
\hline Non-smoking related & 94 & 128 & $0.68(0.47$ to 0.99$)$ & $0.29(0.09$ to 0.90$)$ & $0.83(0.56$ to 1.21$)$ \\
\hline
\end{tabular}

${ }^{*}$ Calculated using Cox proportional hazards modelling, adjusted for age, sex, smoking, and incident cancer. 
Table 5| Distribution of incident cancer in participants with any dementia and matched controls

\begin{tabular}{|c|c|c|c|}
\hline Cancer type & Total No & No $(\%)$ of cases $(n=495)$ & No $(\%)$ of controls $(n=1485)$ \\
\hline Overall & 252 & $41(8.3)$ & 211 (14.2) \\
\hline Non-smoking related & 171 & $27(5.5)$ & $144(9.7)$ \\
\hline Smoking related & 81 & $14(2.8)$ & $67(4.5)$ \\
\hline Cancers on routine screening & 119 & $17(3.4)$ & $102(6.9)$ \\
\hline Colorectal & 49 & $10(2.0)$ & $39(2.6)$ \\
\hline Lung & 36 & $3(0.6)$ & $33(2.2)$ \\
\hline Breast & 35 & $4(0.8)$ & $31(2.1)$ \\
\hline Prostate & 27 & $2(0.4)$ & $25(1.7)$ \\
\hline Bladder & 21 & $7(1.4)$ & $14(0.9)$ \\
\hline Haematological & 12 & $2(0.4)$ & $10(0.7)$ \\
\hline Unknown primary & 10 & $3(0.6)$ & $7(0.5)$ \\
\hline Melanoma & 8 & $1(0.2)$ & $7(0.5)$ \\
\hline Pancreas & 7 & $1(0.2)$ & $6(0.4)$ \\
\hline Kidney & 6 & $0(0.0)$ & $6(0.4)$ \\
\hline Lymph nodes & 5 & $1(0.2)$ & $4(0.3)$ \\
\hline Stomach & 4 & $1(0.2)$ & $3(0.2)$ \\
\hline Corpus uteri & 4 & $0(0.0)$ & $4(0.3)$ \\
\hline Head and neck & 3 & $0(0.0)$ & $3(0.2)$ \\
\hline Liver & 3 & $0(0.0)$ & $3(0.2)$ \\
\hline Male breast & 3 & $1(0.2)$ & $2(0.1)$ \\
\hline Brain & 3 & $1(0.2)$ & $2(0.1)$ \\
\hline Oesophagus & 2 & $2(0.4)$ & $0(0.0)$ \\
\hline Gallbladder & 2 & $0(0.0)$ & $2(0.1)$ \\
\hline Thyroid & 2 & $0(0.0)$ & $2(0.1)$ \\
\hline Connective tissue & 2 & $1(50.0)$ & $1(50.0)$ \\
\hline Cervix & 2 & $0(0.0)$ & $2(100.0)$ \\
\hline Ovary & 2 & $1(50.0)$ & $1(50.0)$ \\
\hline Small intestine & 1 & $0(0.0)$ & $1(100.0)$ \\
\hline Pleura & 1 & $0(0.0)$ & $1(100.0)$ \\
\hline Bone & 1 & $0(0.0)$ & $1(100.0)$ \\
\hline Female genitalia & 1 & $0(0.0)$ & $1(100.0)$ \\
\hline
\end{tabular}


Table 6 | Nested case-control study of confirmed dementia and incident cancer in Framingham Heart Study

\begin{tabular}{|c|c|c|c|c|c|c|}
\hline \multirow[b]{2}{*}{ Baseline } & \multicolumn{2}{|c|}{ Any dementia ( $n=495)$} & \multicolumn{2}{|c|}{ Possible Alzheimer's disease ( $n=376$ ) } & \multicolumn{2}{|c|}{ Probable Alzheimer's disease $(n=327)$} \\
\hline & $\mathrm{No} / \mathrm{No}^{*}$ & Hazard ratio $(95 \% \mathrm{Cl}) \dagger$ & $\mathrm{No} / \mathrm{No}^{*}$ & Hazard ratio $(95 \% \mathrm{Cl})$ & $\mathrm{No} / \mathrm{No}^{*}$ & Hazard ratio $(95 \% \mathrm{Cl})$ \\
\hline \multicolumn{7}{|l|}{ Any cancer: } \\
\hline Model $1 \ddagger$ & $252 / 1485$ & $0.44(0.32$ to 0.61$)$ & $180 / 1128$ & $0.38(0.25$ to 0.56$)$ & $159 / 981$ & 0.39 (0.26 to 0.58$)$ \\
\hline Model $2 \S$ & $175 / 913$ & $0.38(0.26$ to 0.57$)$ & $123 / 696$ & $0.29(0.17$ to 0.49$)$ & $111 / 599$ & 0.29 (0.17 to 0.49$)$ \\
\hline \multicolumn{7}{|c|}{ Smoking related cancer: } \\
\hline Model 1 & $88 / 1485$ & 0.45 (0.26 to 0.77$)$ & $66 / 1128$ & $0.45(0.24$ to 0.84$)$ & $58 / 981$ & 0.45 (0.24 to 0.88$)$ \\
\hline Model 2 & $61 / 913$ & 0.31 (0.15 to 0.65$)$ & $46 / 696$ & $0.24(0.10$ to 0.61$)$ & $40 / 599$ & 0.21 (0.07 to 0.58$)$ \\
\hline \multicolumn{7}{|c|}{ Non-smoking related cancer: } \\
\hline Model 1 & $178 / 1485$ & 0.45 (0.31 to 0.65$)$ & $126 / 1128$ & $0.36(0.22$ to 0.58$)$ & $110 / 981$ & $0.36(0.21$ to 0.59$)$ \\
\hline Model 2 & $125 / 913$ & $0.42(0.26$ to 0.67$)$ & $86 / 696$ & $0.32(0.17$ to 0.59$)$ & $78 / 599$ & 0.31 (0.16 to 0.59$)$ \\
\hline
\end{tabular}

*Number of cancer cases/number of reference participants.

†Hazard ratio and $95 \%$ confidence interval calculated using Cox proportional hazards modelling. $\ddagger$ Matched on age and sex.

§Additionally adjusted for body mass index and smoking. 